\title{
Non-monotonic dose-response relationships and endocrine disruptors: a qualitative method of assessment
}

\author{
Fabien Lagarde ${ }^{1}$, Claire Beausoleil ${ }^{*}$, Scott M Belcher ${ }^{2}$, Luc P Belzunces ${ }^{3}$, Claude Emond ${ }^{4}$, Michel Guerbet ${ }^{5}$ \\ and Christophe Rousselle ${ }^{1}$
}

\begin{abstract}
Experimental studies investigating the effects of endocrine disruptors frequently identify potential unconventional dose-response relationships called non-monotonic dose-response (NMDR) relationships. Standardized approaches for investigating NMDR relationships in a risk assessment context are missing. The aim of this work was to develop criteria for assessing the strength of NMDR relationships. A literature search was conducted to identify published studies that report NMDR relationships with endocrine disruptors. Fifty-one experimental studies that investigated various effects associated with endocrine disruption elicited by many substances were selected. Scoring criteria were applied by adaptation of an approach previously used for identification of hormesis-type dose-response relationships. Out of the 148 NMDR relationships analyzed, 82 were categorized with this method as having a "moderate" to "high" level of plausibility for various effects. Numerous modes of action described in the literature can explain such phenomena. NMDR can arise from numerous molecular mechanisms such as opposing effects induced by multiple receptors differing by their affinity, receptor desensitization, negative feedback with increasing dose, or dose-dependent metabolism modulation. A stepwise decision tree was developed as a tool to standardize the analysis of NMDR relationships observed in the literature with the final aim to use these results in a Risk Assessment purpose. This decision tree was finally applied to studies focused on the effects of bisphenol A.
\end{abstract}

Keywords: Endocrine disruptors, NMDR, Non-monotonic, Dose-response, Risk assessment, Bisphenol A

\section{Background}

Non-monotonic dose-response (NMDR) relationships are more frequently reported today in experimental studies than they were 10 years ago [1-3]. The endocrine disrupting chemicals (EDCs) are regularly associated with NMDR relationships. Until recently, NMDR relationships were not considered plausible, and thus they were not published, reported, or interpreted as relevant biological phenomena. An increasing number of scientists think that NMDR relationships represent a toxicological reality, but supplementary effort is required to revisit the Paracelsus principle of "the dose makes the poison". Consequently, it is important to avoid rejecting

\footnotetext{
* Correspondence: claire.beausoleil@anses.fr

${ }^{1}$ French Agency for Food, Environmental and Occupational Health \& Safety (ANSES), Risk Assessment Department, 14 rue Pierre et Marie Curie, 94701 Maisons-Alfort Cedex, France

Full list of author information is available at the end of the article
}

studies merely because they do not match the classic toxicological concept of monotonicity. Before affirming that such phenomenon exists in a study, a screening analysis of individual NMDR profile is required to reveal better understanding of the underlying biological mechanism (s) involved and support plausibility of the observed NMDR.

The term "NMDR" describes a dose-response relationship characterized by a curve whose slope changes direction within the range of tested doses. Non-monotonicity represents a challenge to fundamental concepts in toxicology and risk assessment. Indeed, environmental risk assessment approaches used by regulatory agencies around the world were developed on the basis of a methodology published by the National Academy of Sciences [4]. For the hazard characterization step, it is generally accepted that once detectable, a response of an organism to a toxicant increases proportionally with the 
level of exposure until reaching an upper-limit or maximaleffect level $\left(E_{\max }\right)$ beyond which increasing toxicant dose will not increase the response (known as a monotonic dose-response). To assess the dose-response relationship of a chemical, several doses are typically tested to define the no observed adverse effect level (NOAEL) and/or the lowest observed adverse effect level (LOAEL). The NOAEL is considered a conservative default threshold below which a chemical is not expected to induce adverse effects, irrespective of the dose [5].

In contrast to this well-accepted hyperbolic or curvilinear dose-response relationship, which when plotted as toxicant effect (ordinate) and the logarithm $(\log 10)$ of dose (abscissa) results in a sigmoidal shaped curve, a NMDR relationship may present as a bell-shaped profile. This profile, also called inverted-U shape, is characterized by responses at intermediate dose (s) and a decreased response or no response observed at low- and high-exposure levels. Also observed in the literature are U-shaped profiles with the highest responses at low- and high-exposure levels. In such cases, the standard notion of threshold, as defined by the NOAEL concept, is not inclusive of all potentially harmful effects. As clearly stated by Vandenberg et al. [3], "if a non-monotonic relationship occurs between the doses tested in traditional toxicology studies (i.e. the NOAEL or NOEL) and the calculated "safe" or reference dose, this would still have serious implications for risk assessment". Thus, the standard approaches used for setting safe human and environmental exposure levels by extrapolation from high dose testing might not be applicable in case of NMDR profiles. There is a class of toxicants (i.e., EDCs) for which NMDR relationships, have been experimentally described with relative high frequency compared to other chemicals [6-11]. The EDCs act through several modes of action to cause effects on sensitive tissues. As a result, EDCs can commonly act on many physiological systems in addition to endocrine tissues. Effects observed in sensitive target tissues can also be caused by exposure-related changes in mechanisms governing normal negative feedback regulation of endocrine tissues and hormone secretion; such effects may also influence the dose-response relationship depending on exposure duration. With increasing awareness, more studies are being specifically designed to address whether the doseresponse relationships for EDCs and other chemicals are described with an NMDR curve. As a result, NMDR relationships are being reported with an increasing frequency, which may have consequences for risk assessment. As reported by Vandenberg et al. [3], regardless of mechanistic underpinnings of each NMDR, their existence alone challenged traditional means of risk assessment.

The work described in this manuscript aimed to (1) perform a focused literature review, (2) extract a representative set of observed NMDR relationships for some EDCs and (3) use that information to develop a methodology to assess whether such a reported dose-response relationship is sufficiently reliable in order to be used in risk assessments. The screening analysis method evaluating the likelihood and the plausibility of the biological mechanisms involved was applied for each identified NMDR. Then, a stepwise decision tree was developed as a tool to standardize analysis for data reliability of observed in vivo NMDR relationships for risk assessment.

\section{Methods}

\section{Screening analysis of the literature}

A literature review was conducted by selecting putative EDCs for which one or more NMDR profiles were observed. Many keywords related to EDCs (i.e., hormones or exogenous substances for which a general consensus exists for their endocrine properties) and NMDR relationships were used to search the PubMed database, with a data-lock point of January 2012. The keywords used to screen EDCs were bisphenol* OR phthalate* OR paraben* OR phenol* OR PCB (polychlorinated biphenyls)* OR diethylstilbestrol OR estrogen* OR estradiol*. The keywords used to screen NMDR relationships were hormesis OR hormetic OR non-monotonic OR invertedU OR U-shape* OR J-shape* OR bell-shape* OR biphasic. All published articles outlining an NMDR relationship with a tested compound were selected.

To determine whether the existence of an NMDR relationship was supported by the available data, a qualitative methodology was applied by considering the statistical strength and the biological plausibility of each reported NMDR profile. To assess the statistical strength of NMDR profile, an appropriate statistical analysis based on individual results demonstrating the non-monotonic nature of each dose-response relationship is essential. There were cases in which a proper statistical analysis was not performed by the authors and individual data were poorly reported. Therefore, in these cases, it was difficult to confirm a posteriori that the observed relationships were statistically significant for a non-monotonic behavior. For those cases, specific scoring criteria were applied to assess the strength of the NMDR relationships. This scoring criteria was derived from the identification criteria proposed by Calabrese and Baldwin [12] for hormesis (a specific type of NMDR profile).

The biological plausibility of NMDR relationships reported as significant, or scored to have sufficient strength, were evaluated by considering whether mechanistic explanations were proposed or demonstrated for the observed dose-response relationship. If the proposed hypotheses were supported by experimental evidence, then the biological plausibility was considered as reinforced. 


\section{Stepwise decision tree}

A stepwise decision tree was developed (Figure 1) to assess whether observed NMDR profiles for EDCs could be used in the context of risk assessment. Using this approach, data is first qualified using the Klimisch score as an ancillary approach to assess quality of the study and the experimental data [13]. If the quality is identified as Category 3 or 4 , then the study will be characterized as an inconclusive NMDR relationship.

If the quality of the study is Category 1 or 2 , then we will proceed to the second step and consider the number of tested doses analyzed in the study. If less than or equal to three (inclusive of the negative control), the number of doses will be judged to be insufficient to establish a dose-response relationship and the study is characterized as an inconclusive NMDR relationship.

For studies with more than three doses, the third step depends on the availability (or not) of adequate experimental data to continue the plausibility assessment of a NMDR. To assess the strength of NMDR profile, an appropriate statistical analysis investigating the nonmonotonic nature of each dose-response relationship is most appropriate because it is based on individual results. So when an adequate amount of data is available, a statistical assessment is performed. An NMDR is considered plausible if the results are significant $(\mathrm{p}<0.05)$. However, individual data are often too poorly reported in literature to conduct such statistical analysis although

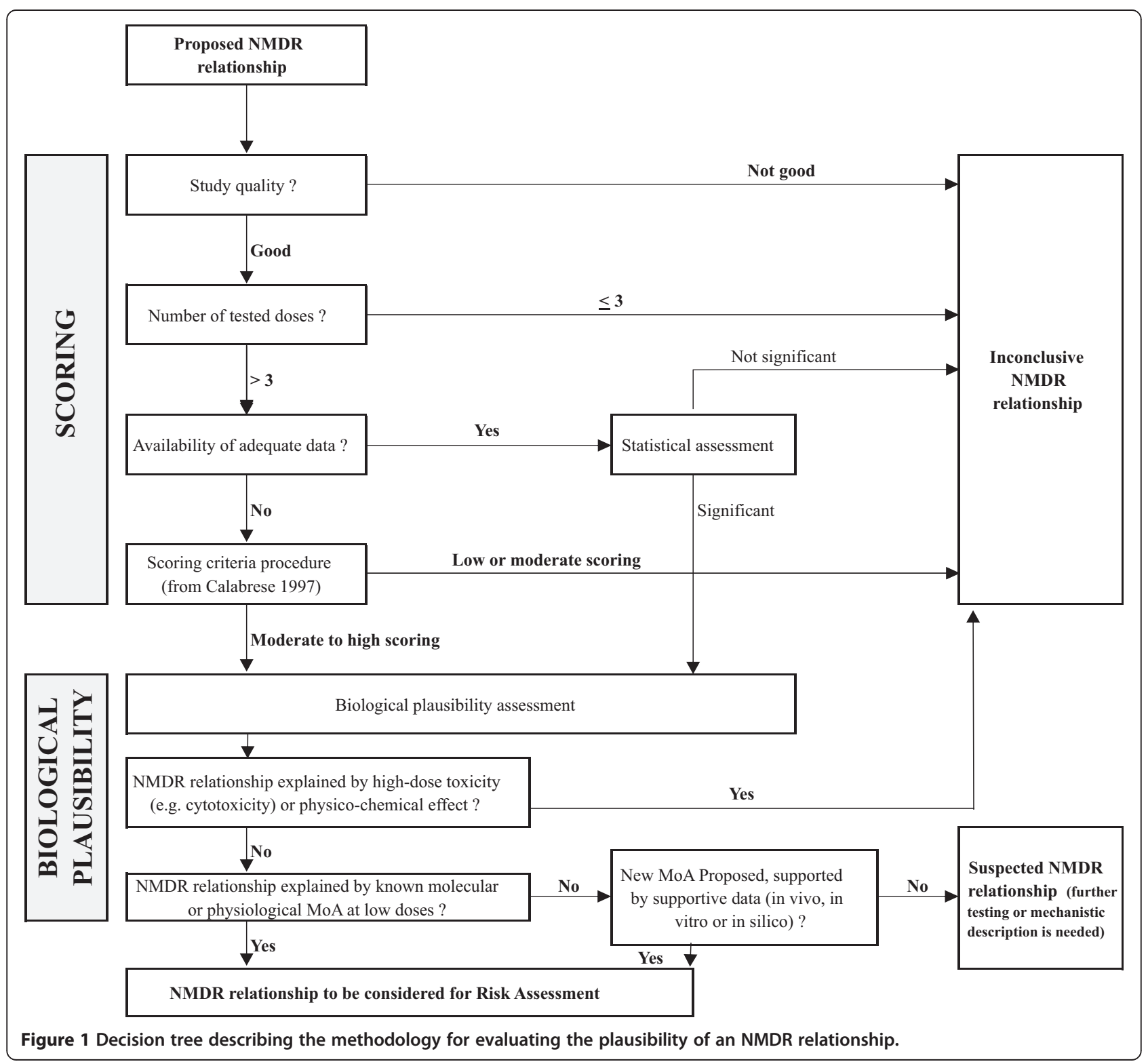


an NMDR might exist. For those cases, a specific scoring procedure is applied in a fourth step to assess the strength of the NMDR relationships. This scoring procedure is derived from the criteria proposed by Calabrese and Baldwin [12] for hormesis (a specific type of NMDR profile). Briefly, the procedure developed by Calabrese and Baldwin is a numeric scoring assignment value including the number of tested dose levels, the magnitude of the response associated with each dose compared to the basal level, the significance of the response at each dose, and the presence of other studies confirming these data (Table 1). These criteria were used because we considered these parameters important and sufficient to define the non-monotonic nature of a dose-response relationship and estimate the plausibility of a presumed NMDR relationship (Table 2). The criteria used here are the criteria suggested by Calabrese and Baldwin adjusted for a use in this application. Each score was assessed individually without

$\begin{aligned} & \text { Table } 1 \text { Summary of criteria of analysis with assigned } \\
& \text { point values used in the evaluation of statistical plausibility } \\
& \text { of an NMDR relationship }\end{aligned}$
\begin{tabular}{ll} 
Number of doses below ZEP (excluding the control) & Score A \\
\hline 1 & 1 \\
2 & 2 \\
3 & 3 \\
4 & 4 \\
$\geq 5$ & 5
\end{tabular}

Experimental determination of ZEP

Yes

No

Number of doses statistically different from control 1

2

3

$\geq 4$

Reproducibility of the dose-response relationship

Yes

No

Magnitude of response (percentage control value)

Inverted-U curve

$\geq 100 \%$, $\leq 125 \%$

$>125 \%, \leq 150 \%$

$>150 \%, \leq 200 \%$

$>200 \%, \leq 400 \%$

$>400 \%$

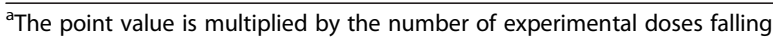
within the corresponding percentage range.

Criteria reported (Table 1) were extracted from Calabrese and Baldwin [12]. The ZEP (zero equivalent point) corresponds to the point where the response crosses the control value in a hormetic effect.
Table 2 Summary of total score for plausibility of an NMDR relationship

\begin{tabular}{ll}
\hline Total score $^{\text {a }}$ & Plausibility of an NMDR relationship \\
\hline $1-2$ & No-low \\
$>2-8$ & Low \\
$>8-12$ & Low-moderate \\
$>12-16$ & Moderate \\
$>16-20$ & Moderate-high \\
$>20$ & High \\
\hline
\end{tabular}

${ }^{\mathrm{a}}$ These scores were extracted from Calabrese and Blain (2011) [14].

considering whether NMDR relationships were reported or not in the same study. A score of "moderate," "moderate-high" or "high" was considered in this work as indicative of a sufficient strength. The fifth and last step of the assessment is to determine whether the previously suspected NMDR relationship is also supported by biological plausibility. So an additional assessment of the literature is made to check whether additional information would support the biological plausibility and then increase the confidence in the reported NMDR.

The biological plausibility of NMDR relationships reported as significant, or scored to have sufficient strength, is evaluated by considering whether mechanistic explanations are proposed or demonstrated for the observed dose-response relationship: (1) the NMDR relationship is explained or not by high-dose toxicity (e.g., cytotoxicity) or physico-chemical effects, (2) a known or proposed mechanism of action that could explain the observed effect is described, or (3) the existence of in vivo, in vitro, or in silico experimental data that support a new mechanism of action. If the proposed hypotheses are supported by experimental evidence, then the biological plausibility is considered as reinforced. In this case, the study is considered as conclusive and qualified useful for risk assessment. If it is concluded that there is a lack of biological plausibility in the study or that a mechanistic explanation or a hypothesis is not developed by the authors, the NMDR is scored as a suspected NMDR, needing either further testing or mechanistic studies.

Lastly, the developed stepwise decision tree is applied to a case study focused on BPA in vivo studies showing NMDR. This case study was selected because the literature search results identified several in vivo studies depicting or claiming NMDRs with this compound and because of the particular interest of the ANSES Working Group on Endocrine Disrupters and on BPA in particular, which was under evaluation by this committee.

\section{Results}

Literature review of studies describing NMDR relationships The first step of this analysis was to perform a targeted literature search, which identified 219 publications in 
the PubMed database up to January 2012. Of these publications, 51 experimental studies described one or more NMDR profiles concerning EDCs and/or natural hormones. Out of these 51 studies, 2 were epidemiological studies $[15,16], 20$ were in vitro studies [6,17-35], and 29 were in vivo studies [36-64]. From these 51 studies, 170 dose-effect relationships were claimed by the authors as NMDR, most of them involving an endocrine disruption (Table 3). The most often-cited substances were BPA and $17 \beta$-estradiol $\left(\mathrm{E}_{2}\right)$.

The NMDR profiles were reported for both animal sexes, for various physiological and behavioral effects, and for several organs or systems (Table 4). Affected organs and systems included the central nervous system, hypothalamic-pituitary axis, mammary glands, adrenal glands, the cardiovascular system, and the male and female reproductive systems. In 4 studies [26-29], the effects having the highest occurrence were related to modulation of prolactin release (12 NMDR relationships) and changes in protein kinase activity (11 NMDR relationships) in pituitary cells. A modification of the mammary structure in mice (e.g., numbers and volume of terminal end buds and density of the mammary epithelium) was reported in 6 publications in which 15

Table 3 EDCs and the number of associated NMDR relationships

\begin{tabular}{|c|c|c|}
\hline Substance & & $\begin{array}{l}\text { Number of NMDR } \\
\text { relationships }\end{array}$ \\
\hline \multirow[t]{7}{*}{ Hormone } & & 42 \\
\hline & $17 \beta$-estradiol & 35 \\
\hline & 17a-estradiol & 2 \\
\hline & Ethinyl estradiol & 2 \\
\hline & Dihydrotestosterone & 1 \\
\hline & Pregnenolone & 1 \\
\hline & Dehydroepiandrosterone & 1 \\
\hline Bisphenol A & & 60 \\
\hline Alkylphenols & & 16 \\
\hline Diethylhexylphthalate & & 10 \\
\hline \multirow[t]{6}{*}{ Phytoestrogens } & & 10 \\
\hline & Coumestrol & 2 \\
\hline & Daidzein & 2 \\
\hline & Genistein & 3 \\
\hline & Lavendustin & 1 \\
\hline & Resveratrol & 2 \\
\hline \multirow[t]{3}{*}{ Pesticide } & & 12 \\
\hline & Organochlorine & 9 \\
\hline & Methoxychlor & 3 \\
\hline PCBs & & 9 \\
\hline Diethylstilbestrol & & 12 \\
\hline
\end{tabular}

NMDR profiles were identified $[39,47,57,58,60,61]$. It is important to note that some NMDR relationships observed with $\mathrm{BPA}$ and $\mathrm{E}_{2}$ were related to modes of action mediated by estrogen receptors and rapid signaling mechanisms. These effects include the release of prolactin and the phosphorylation of protein kinases in pituitary cells, cardiomyocyte contractility, structural modifications of mammary terminal end buds, and modification of epididymal weight. Additionally, the epidemiological studies identified 8 NMDR profiles for metabolic effects associated with endpoints such as increased body mass index, insulin resistance, altered triglycerides and high-density lipoprotein (HDL) levels, and increased risk of soft-tissue sarcoma.

\section{Quality analysis of NMDR relationships}

To evaluate the plausibility of the NMDR profiles observed, a series of criteria was applied based on those developed by Calabrese and Baldwin [12]. The first criterion was the minimal number of dose tested levels. To be considered acceptable, in addition to control group to establish endpoint baseline, a minimum of 3 dose levels were required.

NMDR relationships were reported in 2 epidemiological studies $[15,16]$. Both studies were analyzed to assess the plausibility of the dose response relationship reported by the authors. Regarding the study from Tuomisto et al. [15], the scoring criteria procedure could not be applied due to data inconsistencies. It was concluded that the available data were not appropriate for scoring. This conclusion was reached because the exposure range was treated inconsistently and in a manner that resulted in diverging conclusions regarding the shapes of reported dose-response curves. For example, in the case of dioxins, when the analysis was performed with the World Health Organization's toxicity equivalent (WHO-TEQ) expressed in septiles, the soft tissue sarcoma risk was higher in the lowest septile than in the other septiles, and the differences from control was significant in the second and the sixth septiles. However, when the analysis was performed with WHO-TEQ expressed in quintiles, the odds ratios were not significantly different. Moreover, when confounders such as sex, age, or education were included in the analysis, the odds ratios were decreased in a linear manner. For those reasons, it is unclear whether the observed, decreasing trend of soft tissue sarcoma risk with increasing exposure to dioxin is non-monotonic. Regarding the study from Lee et al. [16], many significant associations of persistent organic pollutants (POPs) with dysmetabolic conditions appeared at a low dose range, suggesting an inverted U-shaped dose-response relationship. As a result, a quadratic relationship was considered in specific statistical tests that supported the significance of several endpoints for some POP exposures. Examples 
Table 4 The effects associated with NMDR relationships

\begin{tabular}{|c|c|c|c|c|}
\hline \multirow{2}{*}{\multicolumn{2}{|c|}{$\begin{array}{l}\text { Organs and biological } \\
\text { functions involved }\end{array}$}} & \multicolumn{2}{|c|}{ Observed effect (with number of associated NMDR relationships) $^{a}$} & \multirow[t]{2}{*}{ Substances involved } \\
\hline & & In vitro studies & In vivo studies & \\
\hline \multicolumn{2}{|l|}{ Hypothalamus } & Dopaminergic transmission (2) & Aromatase activity in preoptic area (1) & $\begin{array}{l}\text { E2, octylphenol, } \\
\text { diethylhexylphthalate } \\
\text { (DEHP) }\end{array}$ \\
\hline \multicolumn{2}{|l|}{ Pituitary gland } & $\begin{array}{l}\text { Cell proliferation (1) GABAergic } \\
\text { transmission (2) Calcium channel activity } \\
\text { (2) Luteinizing hormone (LH) release } \\
\text { (1) Prolactin release (12) Protein kinase } \\
\text { modification (11) }\end{array}$ & $\begin{array}{l}\text { Follicle stimulating hormone (FSH) } \\
\text { plasma level (1) LH plasma level (1) }\end{array}$ & $\begin{array}{l}\text { E2, phytoestrogens, } \\
\text { BPA, alkylphenols, } \\
\text { DES, organochlorines }\end{array}$ \\
\hline \multirow[t]{5}{*}{$\begin{array}{l}\text { Male reproductive } \\
\text { system }\end{array}$} & Testes & $\begin{array}{l}\text { Cell proliferation (1) } \\
\text { Spermatid DNA breaks (1) }\end{array}$ & $\begin{array}{l}\text { Weight (2) Testosterone hydroxylase } \\
\text { activity (4) }\end{array}$ & E2, BPA, ethinyl estradiol \\
\hline & Epididymis, & & Weight (2) & $\mathrm{E} 2, \mathrm{BPA}$ \\
\hline & $\begin{array}{l}\text { seminal } \\
\text { vesicle, }\end{array}$ & & Weight (1) & BPA \\
\hline & $\begin{array}{l}\text { preputial } \\
\text { glands, }\end{array}$ & & Weight (1) & BPA \\
\hline & prostate & Cell proliferation (1) & Weight (5) & $\begin{array}{l}\text { E2, BPA, DES, } \\
\text { dihydrotestosterone } \\
\text { (DHT), alkylphenols }\end{array}$ \\
\hline \multirow[t]{2}{*}{$\begin{array}{l}\text { Female reproductive } \\
\text { system }\end{array}$} & Ovary & $\begin{array}{l}\text { Progesterone secretion (1) Testosterone } \\
\text { secretion (1) Estradiol secretion (1) }\end{array}$ & Transcriptional activity (1) & PCBs, BPA \\
\hline & Uterus & & $\begin{array}{l}\text { Percentage of epithelial cells ERa }+(1) \\
\text { Progesterone receptor expression (1) }\end{array}$ & BPA \\
\hline \multicolumn{2}{|l|}{ Breast } & & $\begin{array}{l}\text { Modification of mammary epithelium } \\
\text { and terminal end buds (15) }\end{array}$ & E2, BPA, DES \\
\hline \multicolumn{2}{|l|}{ Brain } & $\begin{array}{l}\text { L-prostaglandin synthase activity (2) } \\
\text { Calcium channel activity (2) }\end{array}$ & & $\begin{array}{l}\text { E2, pregnenolone, } \\
\text { dehydroepiandrosterone } \\
\text { (DHEA) }\end{array}$ \\
\hline \multirow{2}{*}{$\begin{array}{l}\text { Cardiovascular } \\
\text { system }\end{array}$} & Heart & Myocyte contractility (3) & & E2, BPA \\
\hline & $\begin{array}{l}\text { aortic } \\
\text { smooth } \\
\text { muscle }\end{array}$ & $\begin{array}{l}\text { Cell proliferation (1) Intracellular pH (1) } \\
\text { Modification of protein kinase (2) }\end{array}$ & & E2, BPA \\
\hline \multicolumn{2}{|l|}{ Adrenal glands } & & Corticosterone plasma level (1) & PCBs \\
\hline \multicolumn{2}{|l|}{ Liver } & & $\begin{array}{l}\text { Nuclear receptors expression (5) } \\
\text { Transcriptional factors expression (4) }\end{array}$ & BPA \\
\hline \multicolumn{2}{|l|}{ Perinatal development } & & $\begin{array}{l}\text { Age of puberty (1) Number of newborns } \\
\text { (2) Weight of newborns (4) Anogenital } \\
\text { distance (3) Sex-ratio (2) Newborn } \\
\text { viability (3) Femur length (1) Growth (1) }\end{array}$ & $\begin{array}{l}\text { BPA, DEHP, DES, ethinyl } \\
\text { estradiol, alkylphenols, } \\
\text { methoxychlor, } \\
\text { organochlorines }\end{array}$ \\
\hline \multicolumn{2}{|l|}{ Behavior } & & $\begin{array}{l}\text { Immobility period (1) Spatial memory (2) } \\
\text { Temporal memory (2) Nocturnal activity (1) } \\
\text { Territorial urine-marking (1) Sexual behavior (5) }\end{array}$ & $\begin{array}{l}\text { E2, 17a-estradiol, } \\
\text { BPA, DES }\end{array}$ \\
\hline \multirow[t]{2}{*}{ Metabolism } & Lipids & $\begin{array}{l}\text { Adiponectin release (2) } \\
\text { Adiponectin expression (1) }\end{array}$ & $\begin{array}{l}\text { Triglycerides levels (1) Lipogenesis gene } \\
\text { expression (10) Cholesterol metabolism } \\
\text { gene expression (4) }\end{array}$ & BPA \\
\hline & Glucose & & $\begin{array}{l}\text { Glucose metabolism gene expression (2) } \\
\text { Insulin levels (1) }\end{array}$ & BPA \\
\hline \multicolumn{2}{|l|}{ Immunity } & Mast cells degranulation (4) & $\begin{array}{l}\text { Rate of degranulated eosinophils and } \\
\text { last cells (1) Macrophagic activity (1) } \\
\text { Severity of allergic skin lesions (1) }\end{array}$ & $\begin{array}{l}\text { E2, organochlorines, } \\
\text { alkylphenols, DEHP }\end{array}$ \\
\hline \multicolumn{2}{|l|}{ Cancer } & & $\begin{array}{l}\text { Tumor multiplicity (1) Tumor volume (1) } \\
\text { Latency period for first tumor (1) } \\
\text { Percentage of lung metastases (1) }\end{array}$ & BPA \\
\hline
\end{tabular}


of these exposures for high density lipoproteins (HDL) cholesterol level include p,p'-dichlorodiphenyldichloroethylene (DDE), polychlorobiphenyls (PCB-170, and PCB-206). Examples of these exposures for triglyceride levels include $\mathrm{p}$, p'-DDE, oxychlordane, and trans-nanochlor. Based on the statistically significant results of the reported NMDR relationship, it was then unnecessary to use the criteria analysis derived from Calabrese and Baldwin [12]. Decision not to further consider this study was made mainly because of the categorical classification of exposure which results in the ability to only associate a dose range, rather than a specific exposure, to an observed outcome. Therefore a decision was made not to include a detailed and specific assessment of these two epidemiological studies.

Of the 162 NMDR profiles reported in the selected in vitro and in vivo studies, 14 were rejected for at least one reason (number of tested doses less than 4 , absence of control, no individual numerical values, or absence of statistical tests assessing the significance of the differences between measured values). In some studies (e.g. $[39,46,49,60])$, the authors documented specific statistical analyzes that were considered to be valid or to satisfy criteria for non-monotonicity. The dose-response relationships were therefore considered having a high plausibility for non-monotonicity. In the other studies reviewed, no specific statistical analysis was used to verify the non-monotonic nature of the dose-response relationships. The remaining 148 NMDR relationships were then analyzed using the adapted scoring criteria (Table 5). Out of those 148 reported NMDR relationships, 82 were concluded to have moderate, moderate-high, or high plausibility of being non-monotonic. There were no NMDR profiles classified in the "no-low" plausibility category, mainly because dose-effect relationships identified from studies with only three tested doses, including the control, were $a$ priori rejected and unscored.

\section{Biological plausibility analysis}

In 20 out of the 51 experimental studies, no mechanistic hypothesis for the observed NMDR relationships was proposed by the authors. In the 31 remaining studies, the authors suggested multiple physiological mechanisms to explain the observed effects. Proposed mechanisms or

Table $\mathbf{5}$ The statistical plausibility of NMDR relationships

\begin{tabular}{llll}
\hline Plausibility of NMDR relationships & $\mathbf{n}$ (in vitro) & $\mathbf{n}$ (in vivo) & $\mathbf{n}$ (total) \\
\hline No-low & 0 & 0 & 0 \\
Low & 9 & 29 & 38 \\
Low-moderate & 9 & 20 & 29 \\
Moderate & 9 & 17 & 26 \\
Moderate-high & 6 & 10 & 16 \\
High & 20 & 20 & 40 \\
\hline
\end{tabular}

Note: $n=$ the number of NMDR relationships. mode of action included actions at several molecular targets (e.g., receptors, ion channels and signaling proteins) with differing affinities for the substance, the induction of antagonistic effects, negative feedback regulation to reduce responses, or receptor desensitization. Additional factors proposed as possibly responsible for NMDR relationships included dose-dependent metabolism modulation, high dose toxicity, and/or a dose-dependent protein ionization to generate chaotropic modulation of activity (Table 6).

The most frequent hypothesis proposed to explain NMDR profiles was related to induction of opposing effects (e.g., agonist versus antagonist) across the range of the tested doses. These effects could be initiated by several molecular targets (predominantly receptors) that could be differentially activated by the same substance at different concentration levels and would be dependent on the affinity of the targets for the substance (Figure 2). This differential activation could be exemplified by several studies conducted on substances such as BPA, $E_{2}$, phytoestrogens, diethylstilbestrol [DES] with known differences in affinity for ER $\alpha$ and ER $\beta$, which can induce opposing effects in various cells, tissues, or organs at specific concentration levels $[6,18,27,43,60,61]$. Moreover, two studies described an altered balance between proliferative and proapoptotic effects potentially arising from differential receptor activation at different doses [16,45].

Another commonly proposed hypothesis to explain an observed NMDR was negative feedback regulation mechanisms related to physiological endocrine control of hormone actions $[65,66]$. However, in most of the studies identified, the authors considered that other unknown factors, in addition to negative feedback regulation, were necessary to result in the observed doseresponse relationships.

Receptor desensitization could also explain NMDR relationships (Figure 3). This phenomenon generally results from a mechanism involving protein phosphorylation, endocytosis, or repression of target receptor expression, leading to decreased receptor activity and insensitivity of

Table 6 Mechanistic hypotheses reported in corresponding studies

\begin{tabular}{ll}
\hline Mechanistic hypotheses & References \\
\hline $\begin{array}{l}\text { Existence of several molecular targets } \\
\text { with different affinities and opposite }\end{array}$ & {$[6,16,18,19,24,26-28,34,38,42,43$,} \\
effects & \\
Negative feedback phenomenon & {$[6,25,31,36,47,50,57,58,60,61,63]$} \\
High-dose receptor desensitization & {$[25,44,52]$} \\
$\begin{array}{l}\text { Dose-dependent metabolism } \\
\text { modulation }\end{array}$ & {$[16,38]$} \\
High-dose toxicity & {$[41,47,49]$} \\
Dose-dependent protein ionization & {$[35]$} \\
\hline
\end{tabular}




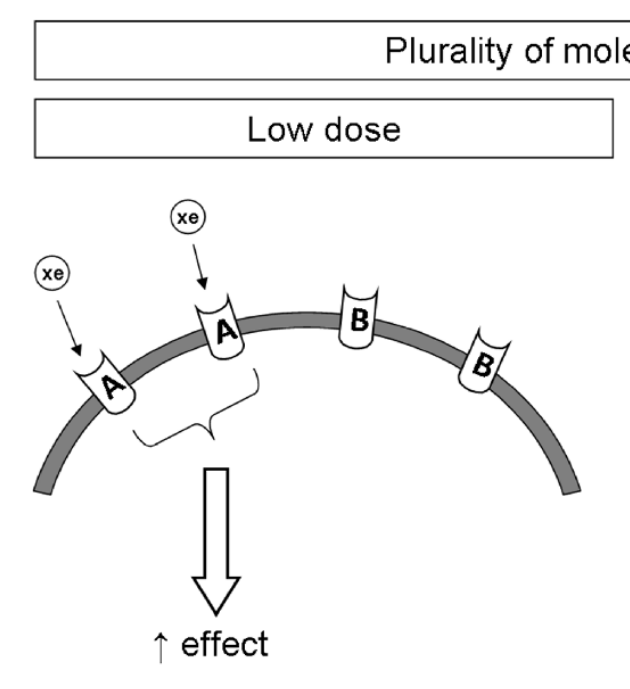

\section{ecular targets}

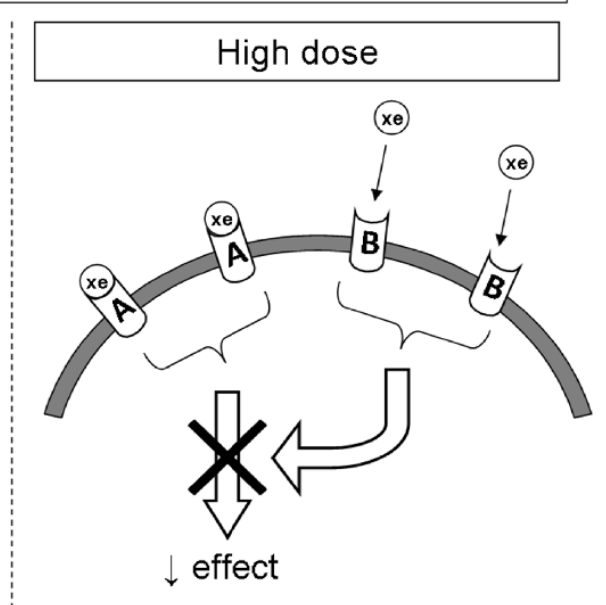

Figure 2 Mechanism of the NMDR relationship phenomenon induced by the "plurality of molecular targets". At low concentrations, EDC binds to the A receptors and induces the observed effect. At high concentrations, the A receptors are still activated and EDC binds to the B receptors, which induces the opposite effect, resulting in an NMDR. Notes: $A=$ Receptor A; B = Receptor B; xe=xenobiotic (e.g., EDC); affinity for A > B.

cells/tissues to ligands at higher dose $[67,68]$. Three studies suggested that desensitization, presumably through decreased expression of target receptors (estrogen receptors) after administering a high dose of substance (i.e., DES or $E_{2}$ ), was responsible for the observed NMDR $[25,44,52]$. Time-dependent receptor desensitization is well established for gonadotropin-releasing hormone ( $\mathrm{GnRH})$, which is, at normal pulsatile low concentrations, required for fertility. Higher concentrations of synthetic GnRH agonists initially stimulate testosterone levels, but over time the level of plasma testosterone drastically decreases, resulting in infertility [69]. However, in the previously mentioned studies, specific experiments to address the validity of a mechanism involving time-dependent receptor desensitization or down regulation were not performed.

NMDR relationships may also be caused by metabolic modulation (Figure 4), as suggested in 2 studies [16,38]. Modulation of gene expression due to formation of

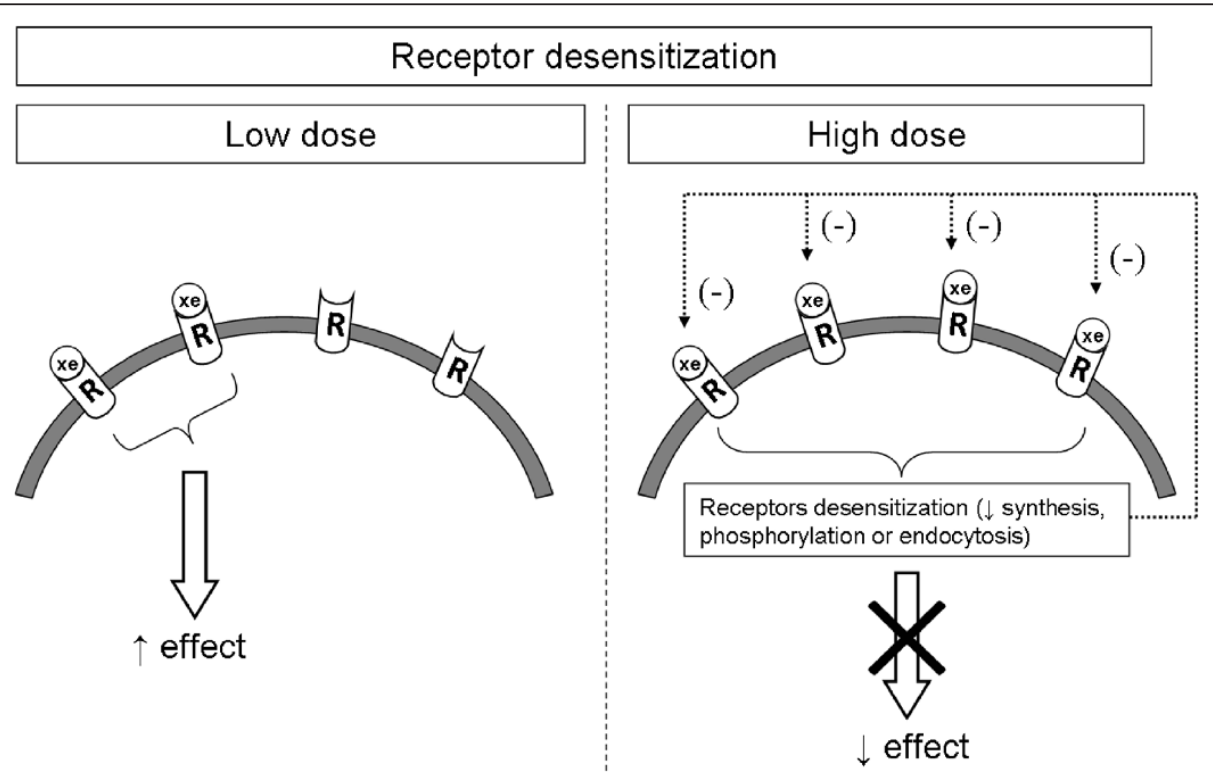

Figure 3 Mechanism of the NMDR phenomenon induced by "receptor desensitization". At low concentrations, EDC binds to some receptors and induces the observed effect. At high concentrations, numerous receptors are bound, resulting in a down-regulation phenomenon characterized by receptor desensitization. Consequently, the intensity of the effect is decreased, resulting in an NMDR. Note: $(-)=$ negative effect; $\mathrm{R}=$ receptor; $\mathrm{xe}=$ xenobiotic (e.g., EDC). 


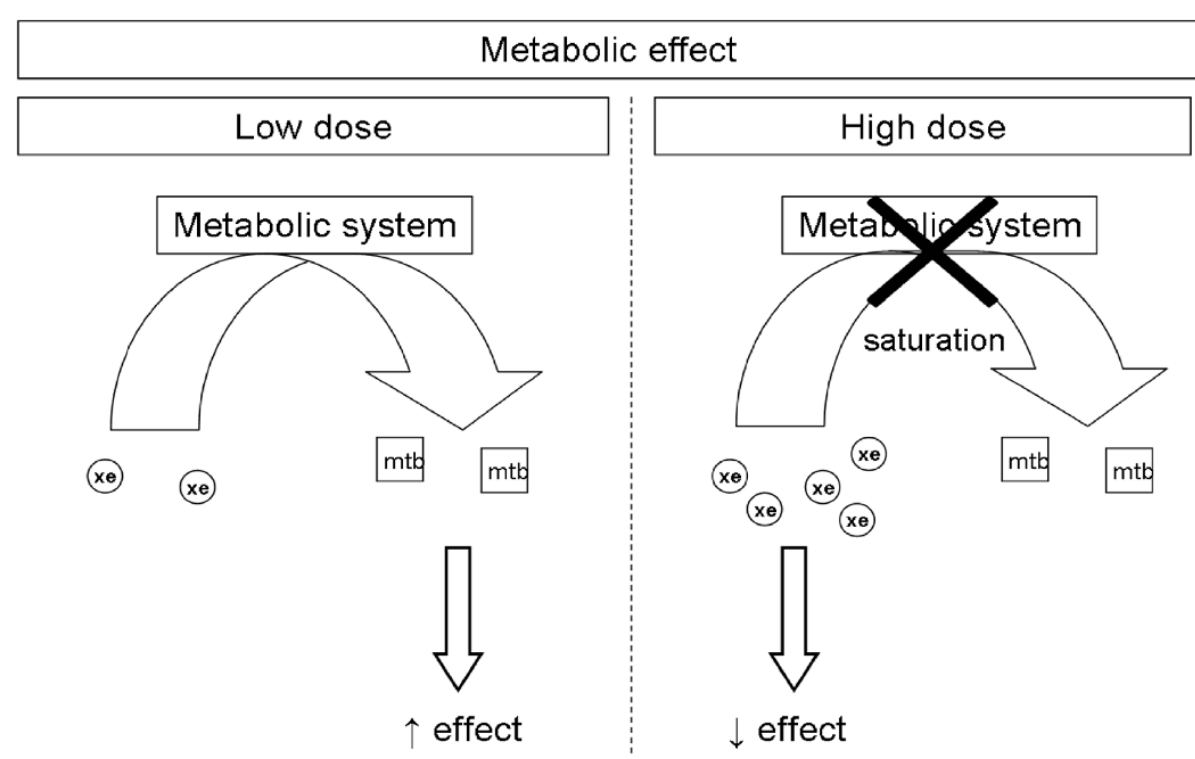

Figure 4 Mechanism of the NMDR relationship phenomenon induced by one of the "metabolic effect" hypotheses. At low concentrations, EDC is catabolized into active metabolites that induce the observed effect. At high concentrations, the metabolic system is saturated, and the parent substance induces an opposite effect, resulting in an NMDR relationship. Note: Mtb = metabolite; xe =xenobiotic (e.g., EDC).

mixed-ligand dimers of steroid hormone receptors was also proposed to explain an observed NMDR (Figure 5) [70].

\section{Stepwise decision tree: case study on BPA}

To consider all criteria in a systematic way, the stepwise decision tree previously described in the Material and
Methods section (Figure 1) was applied to each selected NMDR profile reported for $10 \mathrm{BPA}$ in vivo studies reporting NMDR curves. From these studies, 49 NMDR relationships were identified. There were many effects reported in these studies following exposure to BPA. These effects included an alteration of the response of

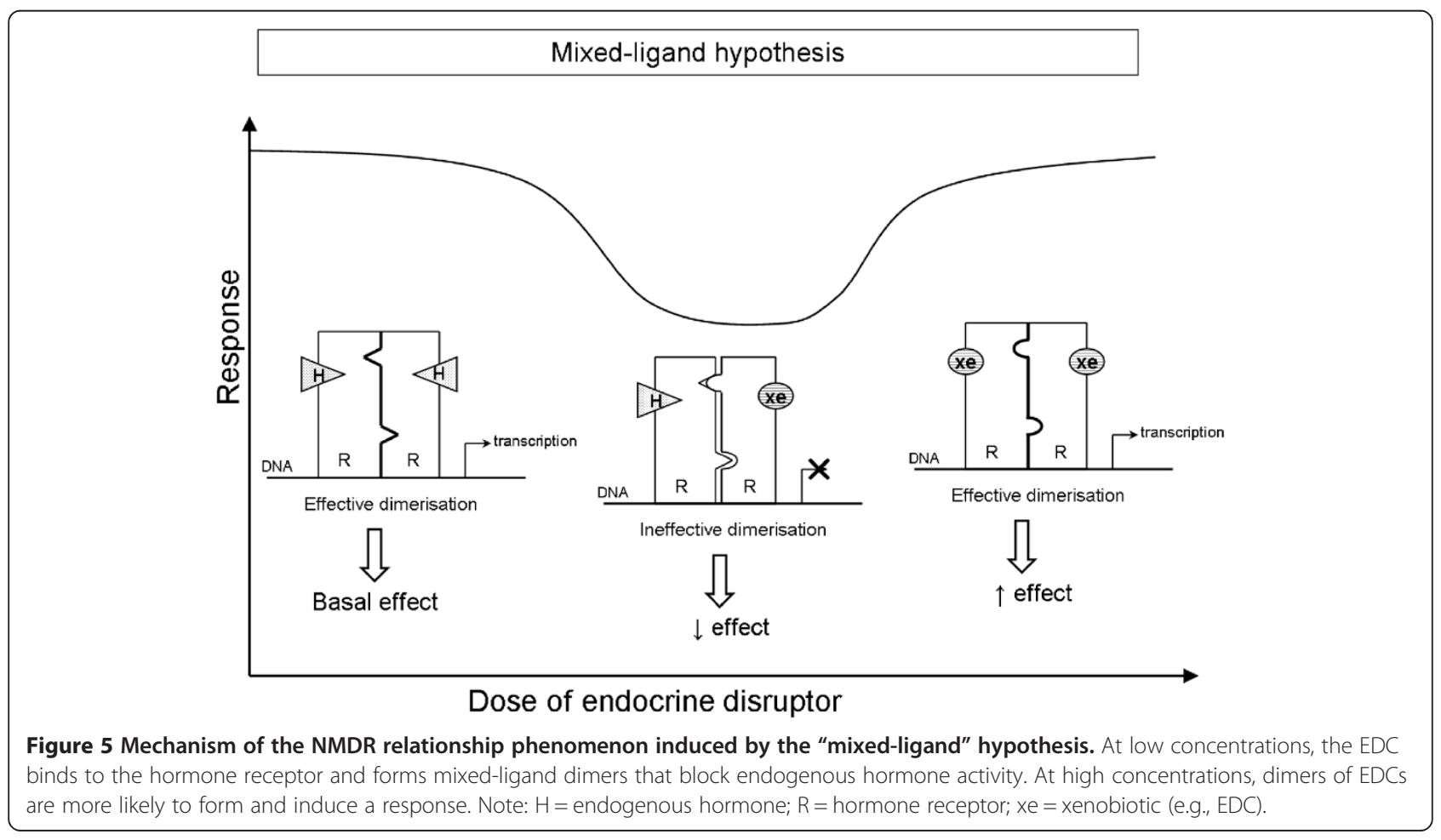


mammary gland to progesterone [39] and increased mammary gland sensitivity to estrogens in mice [71] and increase in mammary tumorigenesis and metastasis in transgenic mice [45]. These effects also included alterations of uterine morphology and expression of estrogen and progesterone receptors in mice [40] and decreased fertility and fecundity in mice [72]. Additional effects included a deficit in the sexual behavior of male rats [46] and alterations in liver expression of several genes involved in lipogenesis [50]. The proposed decision tree could have been used to analyze NMDR relationships observed in in vitro studies. However, since in vitro studies were usually not selected as key studies for quantitative risk assessments, it was therefore decided to focus this analysis on in vivo studies.

\section{Step 1: study quality assessment}

The Klimisch score was used as an ancillary approach to evaluate the quality of the reported experimental data [13]. Klimisch categories 1,2 or 3 are also assigned by the software-based tool "ToxRTool" (Toxicological data Reliability Assessment Tool). This tool was developed within the context of an ECVAM funded project to provide comprehensive criteria and guidance for evaluations of the inherent quality of in vivo and in vitro toxicological data (based on study reports or peer-reviewed publications). As a result, only the dose-responses of studies for which the assigned criteria was Category 1 (reliable without restrictions) or Category 2 (reliable with restrictions) were considered further. None of the retrieved studies followed the Organization for Economic Co-operation and Development's (OECD's) guidelines and/or complied with Good Laboratory Practices. However, because the protocols were well described and results were reported with adequate details, all the identified studies were considered to be Category 2 (reliable with restrictions) and were accepted for further analysis and scoring procedures.

A review of the protocol description indicated that specific parameters related to the external contamination of BPA to the laboratory animals were well controlled in some studies. For example, in the studies of Ayyanan et al. [39], Berger et al. [40], or Jones et al. [46], the mice were bred in a BPA-free environment using polysulfone or polypropylene cages and glass bottles. In the studies of Cabaton et al. [72], the presence of substances that may exhibit estrogenic activities in cages, food, water, and bedding was tested and found to be negligible. In the study of Jenkins et al. [45], the mice were fed phytoestrogen-free food, housed in polypropylene cages, and provided with water in glass bottles. In the study of Marmugi et al. [50], the authors reported using a "standard diet," and no information was provided about the housing conditions, which was considered to be shortcomings [73].

\section{Step 2: number of tested doses (including control)}

In the studies of Adewale et al. [36] and Vom Saal et al. [64], the authors tested only 2 doses and a negative control group. Therefore, no further assessment of these 5 reported NMDR relationships from those studies was possible. For all other in vivo studies, the number of tested doses varied between 4 and 8 , including the negative control group. All NMDR profiles from those studies were scored.

\section{Step 3: availability of adequate data for specific statistical assessment}

In some studies, a posteriori tests performed by the authors such as the Bonferroni multiple comparison test [45,71] or analysis of variance (ANOVA) were used to make comparisons between control and test groups or to determine whether obvious NMDR relationships exhibited a significant quadratic polynomial component $[39,40,46]$. For some studies, sufficient data were not available for specific statistical evaluation of the plausibility of an NMDR profile. In those situations, the analysis criteria adapted from Calabrese and Baldwin was used to provide enough confidence to grade the plausibility of NMDR without a statistical test.

\section{Step 4: criteria analysis procedure}

On the basis of criteria derived from those of Calabrese and Baldwin, 44 in vivo NMDR profiles were analyzed. In one study [45], the available data did not allow us to apply the analysis criteria for one endpoint (time to first tumor latency) and thus the scoring procedure was not performed. Finally, the criteria for 43 in vivo NMDR were applied. Out of these 43 relationships, 23 had a nolow or low-moderate plausibility of being non-monotonic, and 20 had moderate or high and very high likelihood. On the basis of the scoring criteria, the studies in which obvious NMDR could be considered for further analysis of plausibility were those of Jenkins et al. [45], Jones et al. [46], and Marmugi et al. [50].

\section{Step 5: biological plausibility}

The authors of the publications on the 20 dose-response relationships scored with moderate to high and very high plausibility of being non-monotonic proposed two mechanistic explanations: a plurality of molecular targets and/or negative feedback regulation. Jenkins et al. [45] investigated the potential mechanisms behind the NMDR profile. The data suggested that the NMDR profile observed for tumorigenesis was due, at least partially, to the differential ability of BPA to induce apoptosis at each dose. Thus, at high doses of BPA, apoptosis would counter-balance cell proliferation that contributed to tumorigenesis at low doses. Jenkins et al. provided experimental data to support that hypothesis. Jones et al. 
[46] considered the ability of BPA to bind different types of receptors, such as ER $\alpha$, ER $\beta$, androgen receptors or thyroid hormone receptors with different affinities that may explain the NMDR profile observed in male rat sexual behavior. Jones et al. also mentioned the epigenetic activity of BPA as a possible mode of action. However, even if these mechanisms were considered relevant modes of BPA action, no specific experimental data was generated to support these hypotheses for these effects, and then must be considered speculative. In the study of Marmugi et al. [50], molecular mechanisms underlying the observed responses were explored and non doserelated expression of genes involved in lipid metabolism could support their observations. Finally, only the studies of Jenkins et al. and Marmugi et al. could be considered for risk assessment. Whereas the study of Jones et al. could be considered in a risk assessment process if the hypothesis for mode of action is confirmed by further testing.

\section{Discussion}

The purposes of this work were to review the literature to identify NMDR relationships observed for some EDCs, to develop a methodology to assess whether those dose-response relationships were sufficiently reliable for use in risk assessments. In this qualitative approach, a judgment on the quality of the reviewed studies was not introduced, except for the case study on BPA. Rather, the aim was to derive tools that allow consideration of NMDR relationships in risk assessments. In recent years, NMDR profiles have been reported in the literature with an increasing frequency from a variety of in vitro and in vivo toxicological models involving substances that affect hormonal systems [10,74,75]. In an extensive review by Vandenberg et al. [10], they reported hundreds of examples of possible NMDR relationships for more than 20 natural hormones and more than 70 putative EDCs. Those examples were from studies performed in cultured cells, on whole animals or on human. It was not a surprise that such relationships were observed because of the complexity resulting from the many modes of action through which EDCs may influence the actions of hormones. Along with the potential for complex pharmaco/toxicodynamic influences (e.g., expression of varying levels of multiple receptors and possible interactions with native ligands), the critical feedback mechanisms involved with regulation of hormonal systems creates a level of increased complexity. Dose-response relationship for EDCs would reflect this complexity and would likely result in a non-monotonic dose-response. Studies using several hormone-sensitive cell lines have shown that NMDR relationships can result from a variety of mechanisms $[9,76]$. However, that type of relationship is not exclusive to EDCs and is also observed for chemicals substances that do not act on the endocrine system, and can be elicited by non-chemicals stressors, such as ionizing radiations $[7,77]$.

This work intentionally considers the in vivo and the in vitro studies in which the authors of identified publications claimed that the dose-response relationships observed during their experiments had an NMDR profile. Here, the aim was not to compare monotonic doseresponse relationships with NMDR profiles, but to evaluate the plausibility of non-monotonicity when assessing the dose-response relationship from all available data. Indeed, NMDR profiles are still a controversial issue, especially regarding their usefulness for risk assessments $[3,78]$.

In this current study, 51 experimental studies describing 170 NMDR profiles concerning EDCs and/or natural hormones were selected. Out of these 51 investigations, the two epidemiological studies $[15,16]$ were excluded since the scoring criteria procedure was not applied on them.

For the risk assessment point of view, the reproducibility of the effects displaying NMDR profiles should be taken into account because it supports the validity of an observed relationship, and improves the confidence in the biological observations reported. Considering reproducibility of dose-response relationships, most of the in vivo studies reporting NMDR profiles did not lead to further experiments by other scientific teams which prevent to assess their reproducibility. When studies appear to have been replicated, there were often variations in the experimental designs. This can be illustrated by the in vitro studies of Kochukov et al. [28] and Wozniak et al. [34] that both show U-shaped relationships for the effects of BPA on prolactin release from rat pituitary cells. However, due to differences in experimental systems, differences in the shape of the resulting concentrationresponse curves are observed that result in major differences in the apparent potency of BPA.

To some degree, the observation of a NMDR for a compound at different endpoints can increase confidence in the validity of NMDR relationship. In the Marmugi et al. study [50], 18 NMDR profiles related to different metabolic endpoints were reported: regulation of plasma insulin (1 NMDR relationship) and changes in gene expression related to lipid biosynthesis (17 NMDR relationships). In a weight of evidence approach, these observations are considered with lower score compared to NMDR relationships reported from 2 independent studies. It was not the aim of the current study to collect and compare all of the available measurements concerning one compound for the same endpoints. The literature search, as part of the current study, focused only on studies claiming NMDR relationships, which did not afford the opportunity to retrieve studies that do not report NMDR relationships. Therefore, it is currently unfeasible to establish with 
confidence the degree to which specific NMDRs are reproducible.

The scoring assessments used for this current study have been adapted from those previously used by Calabrese and Baldwin and Calabrese ans Blain [12,14] for the quantitative identification of hormesis. We consider these criteria to be a useful starting point to develop a more general approach for analysis of NMDR relationships. As a result of the current study, we have identified some possible limitations of the approach in its current form. For example, the zero equivalent point (ZEP) criteria (Scores A and B) is an arbitrary definition applicable to hormetic responses, which requires reversal of the response and a complete return to the control value. However, this value is not always observed or even expected for EDCs. Future efforts should be made to elaborate more specific criteria that are independent, but inclusive of hormesis, that would result in a generalizable approach. Additionally, it will be necessary to develop a scoring criterion that considers dose range and the number of dose levels.

The specific nature (curve shape) of an NMDR relationship observed from a toxicological assessment has important ramifications for the risk assessment. In different cases, NMDR may be observed in concentration ranges for which the effect is still adverse. Thus, U-shaped doseeffect relationships could be observed with maximal effects at the extreme doses of the U-shape. In this case, it may be expected that at a dose far lower than the lowest tested dose levels, the effect will decrease again, because infinite toxicity cannot be observed at dose levels close to the zero dose. Conversely, bell-shaped dose-effect relationships may be observed with minimal effects induced by the two extreme doses that are not equal to the control response. In this case, at very high doses, unspecific effects will, for example, appear because the organism would be completely overwhelmed by the substance. Thus, it appears credible that U-shaped and bell-shaped doseresponse relationships might correspond to two parts of a same dose-response relationship. At high doses, the substances could impair biological processes by non-specific mechanisms (e.g., choatropic effect, membrane disruption, unspecific binding to proteins). However, because a complete profile is rarely available, we are proposing two ways to use NMDR in risk assessments. For bell-shaped profiles, a NOAEL or a benchmark dose could be extrapolated by modeling the ascending part of the dose-effect relationship. For a U-shaped profile, it could be recommended to experimentally verify, or to model, whether the exposure levels are in the same range of doses for which an NMDR relationship is observed. The main improvement in the testing strategy would be to conduct a better investigation of the dose-response relationship by testing more doses, especially in the lower dose range, as it was proposed during the workshop on "The low dose effects and non-monotonic dose responses for endocrine active chemicals: Science to practice", held in Berlin, Germany, on September 12-14 ${ }^{\text {th }}, 2012$ [79]. These proposals could be included in the revision of OECD's guidelines. If more dose groups are used, then the benchmark dose approach might be preferred because of the possible reduction in the number of animals per dose group. This approach was also proposed at the European Food Safety Authority's $17^{\text {th }}$ Scientific Colloquium on Low Dose Response in Toxicology and Risk Assessment, held in Parma, Italy, on June 14 and 15, 2012 [2].

The relevant EDC modes of action that explain these NMDR relationships are still poorly investigated. Of the BPA studies fully considered, only 1 study explored the hypothesized mechanisms of action [44]. In a recent review from Vandenberg et al. [10], several mechanisms producing NMDR relationships were discussed, but for most of them only hypotheses were proposed which could be considered purely speculative, and their biological basis could not be fully assessed. Mechanisms involved in a non-monotonic profile are often described in vitro, but defining the in vivo mode of action could be much more complicated.

A significant biological plausibility of NMDR does not systematically imply the causality of adverse effects. For the purpose of risk assessments, the endpoints and the potential impact on human health must be considered when defining adversity. Determining whether an effect is adverse can be difficult for subtle or small-magnitude effects. In some situations, as previously mentioned, it would be reasonable to think that some of the effects characterized as presenting an NMDR might have a linkage to compensatory effects and not to endocrine disruption, leading to an adverse effect [7]. However, some of the endpoints identified in this study (Table 3) might be considered to be adverse. Moreover, adversity should also be considered regarding the exposure period. Indeed, there are windows of sensitivity in which specific subpopulations may be more vulnerable [80,81]. In animals, EDCs have the potential to cause reproductive or developmental toxicity or several types of cancers in hormonally responsive organs such as the uterus or the mammary gland in females and the prostate in males $[82,83]$. Thus, biological effects can be reversible or weakly severe in adults, but can be serious and damaging if exposures occur during specific critical life period (often prenatal or perinatal). For some substances, the NMDR profiles are observed exclusively when exposure occurs during a sensitive period of development (i.e., fetuses) when hormone-sensitive tissues such as uterine are most susceptible to the effects of EDCs. Consequently, during the fetal windows, low doses may impair physiological mechanisms responsible for NMDR relationships that do not exist during adulthood $[9,76,81,82]$. 


\section{Conclusions}

For this current work, we developed a methodology to consider individual NMDR relationships in a risk assessment context. We expanded a stepwise decision tree to assess the likelihood of NMDR relationships reported. This analysis can be completed with a weight of evidence approach to evaluate all the data available for the substance of interest. This approach enables assessing the consistency of the dose-response relationship. The steps in this approach involve assembling the relevant data (either positive or negative), evaluating these data for quality and relevance, and integrating the different points of evidence to support conclusions concerning specific properties of the substance. Thus, the relevance and the impact of NMDR relationships reported on EDCs can be better understood and incorporated into the risk assessment method to determine the potential impacts of such substances on human health. Another important point to determine is the extent of experimental exposure (the range of exposure level in which an NMDR relationship occurs). The literature review performed for this current study enabled an analysis of the NMDR relationship profiles reported by the authors.

\begin{abstract}
Abbreviations
ANOVA: Analysis of variance; BPA: Bisphenol A;

DDE: Dichlorodiphenyldichloroethylene; DEHP: Diethylhexylphthalate;

DES: Diethylstilbestrol; DHEA: Dehydroepiandrosterone;

DHT: Dihydrotestosterone; $E_{2}: 17 \beta$-estradiol; EDC: Endocrine disrupting chemical; ER: Estrogenic receptor; HDL: High-density lipoprotein; FSH: Follicle stimulating hormone; GnRH: Gonadotropin-releasing hormone; LH: Luteinizing hormone; LOAEL: Lowest observed adverse effect level; NMDR: Non-monotonic doseresponse; NOAEL: No observed adverse effect level; OECD: Organisation for economic co-operation and development; PCB: Polychlorinated biphenyl; POP: Persistent organic pollutant; WHO-TEQ: World health organization's toxicity equivalent; ZEP: Zero equivalent point.
\end{abstract}

\section{Competing interests}

The authors declare that they have no competing interests.

\begin{abstract}
Authors' contributions
FL, CB and CR have made substantial contributions to conception of the study and interpretation of data, have been involved in drafting the manuscript and revising it critically for important intellectual content, and have given final approval of the version to be published. They agree to be accountable for all aspects of the work in ensuring that questions related to the accuracy or integrity of any part of the work are appropriately investigated and resolved. SMB, LPB, CE and MG have been involved in drafting the manuscript and revising it critically for important intellectual content, and have given final approval of the version to be published. All authors read and approved the final version.
\end{abstract}

\section{Author details}

${ }^{1}$ French Agency for Food, Environmental and Occupational Health \& Safety (ANSES), Risk Assessment Department, 14 rue Pierre et Marie Curie, 94701 Maisons-Alfort Cedex, France. ${ }^{2}$ Department of Pharmacology and Cell Biophysics, University of Cincinnati, College of Medicine, Cincinnati, OH, USA. ${ }^{3}$ INRA, Laboratoire de Toxicologie Environnementale, UR 406 A\&E, CS 40509, 84914 Avignon Cedex 9, France. ${ }^{4}$ BioSimulation Consulting Inc., Newark, DE, USA. ${ }^{5}$ Université de Rouen, UFR Médecine Pharmacie, Laboratoire de Toxicologie, UR 4651 ABTE, 76183 Rouen Cedex 1, France.
}

Received: 14 October 2014 Accepted: 16 January 2015 Published: 11 February 2015

\section{References}

1. Birnbaum LS. Environmental chemicals: evaluating low-dose effects. Environ Health Perspect. 2012;120:143-4.

2. EFSA. EFSA's 17th Scientific Colloquium on low dose response in toxicology and risk assessment: 14-15 June 2012. Parma: [http://www.efsa.europa.eu/fr/ supporting/doc/353e.pdf]

3. Vandenberg LN, Colborn T, Hayes TB, Heindel JJ, Jacobs Jr DR, Lee DH, et al. Regulatory decisions on endocrine disrupting chemicals should be based on the principles of endocrinology. Reprod Toxicol. 2013;38:1-15.

4. National Research Council (NRC). Risk Assessment in the Federal Government: Managing the Process. Washington, DC: The National Academies Press; 1983.

5. Slob W, Pieters MN. A probabilistic approach for deriving acceptable human intake limits and human risks from toxicological studies: general framework. Risk Anal. 1998;18:787-98.

6. Belcher SM, Chen Y, Yan S, Wang HS. Rapid estrogen receptor-mediated mechanisms determine the sexually dimorphic sensitivity of ventricular myocytes to 17 beta-estradiol and the environmental endocrine disruptor bisphenol A. Endocrinology. 2012;153:712-20.

7. Kendig EL, Le HH, Belcher SM. Defining hormesis: evaluation of a complex concentration response phenomenon. Int J Toxicol. 2010;29:235-46.

8. Kohn MC, Melnick RL. Biochemical origins of the non-monotonic receptormediated dose-response. J Mol Endocrinol. 2002;29(1):113-23.

9. WHO-UNEP. State of the Science of Endocrine Disrupting Chemicals. In: Bergman A, Heindel JJ, Jobling S, Kidd KA, Zoeller RT, editors. An assessment of the state of the science of endocrine disruptors prepared by a group of experts. 2012. Available at: <http://www.who.int/ceh/ publications/endocrine/en/index.html> (last accessed (02.02.15). ISBN ISBN: 978-92-807-3274-0.

10. Vandenberg LN, Colborn T, Hayes TB, Heindel JJ, Jacobs Jr DR, Lee DH, et al. Hormones and endocrine-disrupting chemicals: low-dose effects and nonmonotonic dose-responses. Endocr Rev. 2012;33:378-455.

11. Wong JK, Le HH, Zsarnovszky A, Belcher SM. Estrogens and ICl182,780 (Faslodex) modulate mitosis and cell death in immature cerebellar neurons via rapid activation of p44/p42 mitogenactivated protein kinase. J Neurosci. 2003;23:4984-95.

12. Calabrese EJ, Baldwin L. A quantitatively-based methodology for evaluation of chemical hormesis. Hum Ecol Risk Assess. 1997;3(4):545-54.

13. Klimisch HJ, Andreae M, Tillmann U. A systematic approach for evaluating the quality of experimental toxicological and ecotoxicological data. Regul Toxicol Pharmacol. 1997;25:1-5.

14. Calabrese EJ, Blain RB. The hormesis database: the occurrence of hormetic dose responses in the toxicological literature. Regul Toxicol Pharmacol. 2011;61(1):73-81.

15. Tuomisto J, Pekkanen J, Kiviranta H, Tukiainen E, Vartiainen T, Viluksela M, et al. Dioxin Cancer Risk - Example of Hormesis? Dose-response. 2005;3:332-41.

16. Lee DH, Steffes MW, Sjodin A, Jones RS, Needham LL, Jacobs Jr DR. Low dose organochlorine pesticides and polychlorinated biphenyls predict obesity, dyslipidemia, and insulin resistance among people free of diabetes. PLoS One. 2011;6:e15977.

17. Amara JF, Dannies PS. 17 beta-Estradiol has a biphasic effect on gh cell growth. Endocrinology. 1983;112:1141-3.

18. Bouskine A, Nebout M, Brucker-Davis F, Benahmed M, Fenichel P. Low doses of bisphenol A promote human seminoma cell proliferation by activating PKA and PKG via a membrane G-protein-coupled estrogen receptor. Environ Health Perspect. 2009;117:1053-8.

19. Castel H, Louiset E, Anouar Y, Le Foll F, Cazin L, Vaudry H. Regulation of GABAA receptor by protein tyrosine kinases in frog pituitary melanotrophs. J Neuroendocrinol. 2000;12:41-52.

20. Christian M, Gillies G. Developing hypothalamic dopaminergic neurones as potential targets for environmental estrogens. J Endocrinol. 1999;160:1-6.

21. Devidze N, Fujimori K, Urade Y, Pfaff DW, Mong JA. Estradiol regulation of lipocalin-type prostaglandin D synthase promoter activity: evidence for direct and indirect mechanisms. Neurosci Lett. 2010;474:17-21.

22. Emons G, Ortmann O, Thiessen S, Knuppen R. Effects of estradiol and some antiestrogens (clomiphene, tamoxifen, and hydroxytamoxifen) on luteinizing hormone secretion by rat pituitary cells in culture. Arch Gynecol. 1986;237:199-211.

23. Gregoraszczuk EL, Milczarek K, Wojtowicz AK, Berg V, Skaare JU, Ropstad E Steroid secretion following exposure of ovarian follicular cells to three different natural mixtures of persistent organic pollutants (POPs). Reprod Toxicol. 2008;25:58-66 
24. Hugo ER, Brandebourg TD, Woo JG, Loftus J, Alexander JW, Ben-Jonathan N. Bisphenol $\mathrm{A}$ at environmentally relevant doses inhibits adiponectin release from human adipose tissue explants and adipocytes. Environ Health Perspect. 2008:116:1642-7.

25. Incerpi S, D'Arezzo S, Marino M, Musanti R, Pallottini V, Pascolini A, et al. Short-term activation by low 17 beta-estradiol concentrations of the $\mathrm{Na}+/ \mathrm{H}+$ exchanger in rat aortic smooth muscle cells: physiopathological implications. Endocrinology. 2003;144:4315-24.

26. Jeng YJ, Kochukov MY, Watson CS. Membrane estrogen receptor-alphamediated nongenomic actions of phytoestrogens in GH3/B6/F10 pituitary tumor cells. J Mol Signal. 2009;4:2.

27. Jeng YJ, Kochukov M, Watson CS. Combinations of physiologic estrogens with xenoestrogens alter calcium and kinase responses, prolactin release, and membrane estrogen receptor trafficking in rat pituitary cells. Environ Health. 2010;9:61.

28. Kochukov MY, Jeng Y, Watson CS. Alkylphenol xenoestrogens with varying carbon chain lengths differentially and potently activate signaling and functional responses in GH3/B6/F10 somatomammotropes. Environ Health Perspect. 2009;117:723-30.

29. Narita S, Goldblum RM, Watson CS, Brooks EG, Estes DM, Curran EM, et al. Environmental estrogens induce mast cell degranulation and enhance IgE-mediated release of allergic mediators. Environ Health Perspect. 2007:115:48-52.

30. Sargis RM, Johnson DN, Choudhury RA, Brady MJ. Environmental endocrine disruptors promote adipogenesis in the 3 T3-L1 cell line through glucocorticoid receptor activation. Obesity. 2010;18:1283-8.

31. Sonnenschein C, Olea N, Pasanen ME, Soto AM. Negative controls of cell proliferation: human prostate cancer cells and androgens. Cancer Res. 1989:49:3474-81.

32. Wellejus A, Bornholdt J, Vogel UB, Risom L, Wiger R, Loft S. Cell-specific oxidative DNA damage induced by estrogen in rat testicular cells in vitro. Toxicol Lett. 2004;150:317-23.

33. Wetherill YB, Petre CE, Monk KR, Puga A, Knudsen KE. The xenoestrogen bisphenol $\mathrm{A}$ induces inappropriate androgen receptor activation and mitogenesis in prostatic adenocarcinoma cells. Mol Cancer Ther. 2002;1:515-24.

34. Wozniak AL, Bulayeva NN, Watson CS. Xenoestrogens at picomolar to nanomolar concentrations trigger membrane estrogen receptor-alphamediated $\mathrm{Ca} 2+$ fluxes and prolactin release in $\mathrm{GH} 3 / \mathrm{B} 6$ pituitary tumor cells. Environ Health Perspect. 2005;113:431-9.

35. Zylinska L, Gromadzinska E, Lachowicz L. Short-time effects of neuroactive steroids on rat cortical $\mathrm{Ca}^{2+}$-ATPase activity. Biochim Biophys Acta. 1999:1437:257-64.

36. Adewale HB, Jefferson WN, Newbold RR, Patisaul HB. Neonatal bisphenol-a exposure alters rat reproductive development and ovarian morphology without impairing activation of gonadotropin-releasing hormone neurons. Biol Reprod. 2009;81:690-9

37. Adewale HB, Todd KL, Mickens JA, Patisaul HB. The impact of neonatal bisphenol-A exposure on sexually dimorphic hypothalamic nuclei in the female rat. Neurotoxicology. 2011;32:38-49.

38. Andrade AJ, Grande SW, Talsness CE, Grote K, Chahoud I. A dose-response study following in utero and lactational exposure to di-(2-ethylhexyl)-phthalate (DEHP): non-monotonic dose-response and low dose effects on rat brain aromatase activity. Toxicology. 2006;227:185-92.

39. Ayyanan A, Laribi O, Schuepbach-Mallepell S, Schrick C, Gutierrez M, Tanos $T$, et al. Perinatal exposure to bisphenol a increases adult mammary gland progesterone response and cell number. Mol Endocrinol. 2011;25:1915-23.

40. Berger RG, Foster WG, deCatanzaro D. Bisphenol-A exposure during the period of blastocyst implantation alters uterine morphology and perturbs measures of estrogen and progesterone receptor expression in mice. Reprod Toxicol. 2010;30:393-400.

41. Cheng $\amalg$, Cheng TS. Oxidative effects and metabolic changes following exposure of greater duckweed (Spirodela polyrhiza) to diethyl phthalate. Aquat Toxicol. 2012;109:166-75.

42. Dhir A, Kulkarni SK. Antidepressant-like effect of 17beta-estradiol: involvement of dopaminergic, serotonergic, and (or) sigma-1 receptor systems. Can J Physiol Pharmacol. 2008;86:726-35.

43. Gupta C. Reproductive malformation of the male offspring following maternal exposure to estrogenic chemicals. Proc Soc Exp Biol Med. 2000;224:61-8.

44. Inagaki T, Gautreaux C, Luine V. Acute estrogen treatment facilitates recognition memory consolidation and alters monoamine levels in memory-related brain areas. Horm Behav. 2010;58:415-26.
45. Jenkins S, Wang J, Eltoum I, Desmond R, Lamartiniere CA. Chronic oral exposure to bisphenol $A$ results in a nonmonotonic dose-response in mammary carcinogenesis and metastasis in MMTV-erbB2 mice. Environ Health Perspect. 2011;119:1604-9.

46. Jones BA, Shimell JJ, Watson NV. Pre- and postnatal bisphenol A treatment results in persistent deficits in the sexual behavior of male rats, but not female rats, in adulthood. Horm Behav. 2011;59:246-51.

47. Kohlerova E, Skarda J. Mouse bioassay to assess oestrogenic and antioestrogenic compounds: hydroxytamoxifen, diethylstilbestrol and genistein. J Vet Med A Physiol Pathol Clin Med. 2004;51:209-17.

48. Li L, Andersen ME, Heber S, Zhang Q. Non-monotonic dose-response relationship in steroid hormone receptor-mediated gene expression. J Mol Endocrinol. 2007:38:569-85.

49. Love OP, Shutt LJ, Silfies JS, Bortolotti GR, Smits JE, Bird DM. Effects of dietary PCB exposure on adrenocortical function in captive American kestrels (Falco sparverius). Ecotoxicology. 2003;12:199-208

50. Marmugi A, Ducheix S, Lasserre F, Polizzi A, Paris A, Priymenko N, et al. Low doses of bisphenol $\mathrm{A}$ induce gene expression related to lipid synthesis and trigger triglyceride accumulation in adult mouse liver. Hepatology. 2012;55:395-407.

51. Oehlmann J, Schulte-Oehlmann U, Tillmann M, Markert B. Effects of endocrine disruptors on prosobranch snails (Mollusca: Gastropoda) in the laboratory. Part l: Bisphenol A and octylphenol as xeno-estrogens. Ecotoxicology. 2000;9:383-97.

52. Palanza P, Parmigiani S, VomSaal FS. Effects of prenatal exposure to low doses of diethylstilbestrol, o,p'DDT, and methoxychlor on postnatal growth and neurobehavioral development in male and female mice. Horm Behav. 2001:40:252-65.

53. Pelch KE, Carleton SM, Phillips CL, Nagel SC. Developmental exposure to xenoestrogens at low doses alters femur length and tensile strength in adult mice. Biol Reprod. 2012;86:69.

54. Putz O, Schwartz CB, Kim S, LeBlanc GA, Cooper RL, Prins GS. Neonatal low and high-dose exposure to estradiol benzoate in the male rat: I. Effects on the prostate gland. Bio Reprod. 2001;65:1496-505.

55. Putz O, Schwartz CB, LeBlanc GA, Cooper RL, Prins GS. Neonatal low- and high-dose exposure to estradiol benzoate in the male rat: II. Effects on male puberty and the reproductive tract. Biol Reprod. 2001;65:1506-17.

56. Ribeiro AC, Pfaff DW, Devidze N. Estradiol modulates behavioral arousal and induces changes in gene expression profiles in brain regions involved in the control of vigilance. Eur J Neurosci. 2009;29:795-801.

57. Skarda J. Sensitivity and specificity of bioassay of estrogenicity on mammary gland and uterus of female mice. Physiol Res. 2002;51:407-12.

58. Skarda J. Sensitivity and specificity of the bioassay of estrogenicity in mammary gland and seminal vesicles of male mice. Physiol Res. 2002;51:267-76

59. Takano H, Yanagisawa R, Inoue K, Ichinose T, Sadakane K, Yoshikawa T. Di-(2-ethylhexyl) phthalate enhances atopic dermatitis-like skin lesions in mice. Environ Health Perspect. 2006;114:1266-9.

60. Vandenberg LN, Wadia PR, Schaeberle CM, Rubin BS, Sonnenschein C, Soto $\mathrm{AM}$. The mammary gland response to estradiol: monotonic at the cellular level, non-monotonic at the tissue-level of organization? J Steroid Biochem Mol Biol. 2006;101:263-74.

61. Vandenberg LN, Maffini MV, Schaeberle CM, Ucci AA, Sonnenschein C, Rubin $B S$, et al. Perinatal exposure to the xenoestrogen bisphenol-A induces mammary intraductal hyperplasias in adult CD-1 mice. Reprod Toxicol. 2008:26:210-9.

62. vom Saal FS, Nagel SC, Palanza P, Boechler M, Parmigiani S, Welshons WV. Estrogenic pesticides: binding relative to estradiol in MCF-7 cells and effects of exposure during fetal life on subsequent territorial behaviour in male mice. Toxicol Lett. 1995;77:343--350.

63. vom Saal FS, Timms BG, Montano MM, Palanza P, Thayer KA, Nagel SC, et al. prostate enlargement in mice due to fetal exposure to low doses of estradiol or diethylstilbestrol and opposite effects at high doses. Proc Natl Acad Sci U S A. 1997;94:2056-61.

64. VomSaal FS, Cooke PS, Buchanan DL, Palanza P, Thayer KA, Nagel SC, et al. A physiologically based approach to the study of bisphenol A and other estrogenic chemicals on the size of reproductive organs, daily sperm production, and behavior. Toxicol Ind Health. 1998;14:239-60.

65. Berga S, Naftolin F. Neuroendocrine control of ovulation. Gynecol Endocrinol. 2012;28 Suppl 1:9-13.

66. Costa-e-Sousa RH, Hollenberg AN. Minireview: The neural regulation of the hypothalamic-pituitary-thyroid axis. Endocrinology. 2012;153:4128-35. 
67. Bouvier M, Collins S, O'Dowd BF, Campbell PT, de Blasi A, Kobilka BK, et al. Two distinct pathways for CAMP-mediated down-regulation of the beta 2-adrenergic receptor. Phosphorylation of the receptor and regulation of its mRNA level. J Biol Chem. 1989;264:16786-92.

68. Lohse MJ, Benovic JL, Caron MG, Lefkowitz RJ. Multiple pathways of rapid beta 2-adrenergic receptor desensitization. Delineation with specific inhibitors. J Biol Chem. 1990;265:3202-11.

69. Peyromaure M, Rebillard X, Ruffion A, Salomon L, Villers A, Soulie M, et al. Time-course of plasma testosterone in patients with prostate cancer treated by endocrine therapy. Prog Urol. 2008;18:2-8.

70. Maness SC, McDonnell DP, Gaido KW. Inhibition of androgen receptordependent transcriptional activity by DDT isomers and methoxychlor in HepG2 human hepatoma cells. Toxicol Appl Pharmacol. 1998;151:135-42.

71. Wadia PR, Vandenberg LN, Schaeberle CM, Rubin BS, Sonnenschein C, Soto AM. Perinatal bisphenol A exposure increases estrogen sensitivity of the mammary gland in diverse mouse strains. Environ Health Perspect. 2007;115:592-8.

72. Cabaton NJ, Wadia PR, Rubin BS, Zalko D, Schaeberle CM, Askenase MH, et al. Perinatal exposure to environmentally relevant levels of bisphenol A decreases fertility and fecundity in CD-1 mice. Environ Health Perspect. 2011;119:547-52.

73. Thigpen JE, Setchell KD, Kissling GE, Locklear J, Caviness GF, Whiteside T, et al. The estrogenic content of rodent diets, bedding, cages, and water bottles and its effect on bisphenol A studies. J Am Assoc Lab Anim Sci. 2013;52:130-41.

74. Le HH, Belcher SM. Rapid signaling actions of environmental estrogens in developing granule cell neurons Are mediated by estrogen receptor $\beta$. Endocrinology. 2010;151:5689-99.

75. Zsarnovszky A, Le HH, Wang HS, Belcher SM. Ontogeny of rapid estrogenmediated extracellular signal-regulated kinase signaling in the rat cerebellar cortex: potent nongenomic agonist and endocrine disrupting activity of the xenoestrogen bisphenol A. Endocrinology. 2005;146:5388-96.

76. Zoeller RT, Brown TR, Doan LL, Gore AC, Skakkebaek NE, Soto AM, et al. Endocrine-disrupting chemicals and public health protection: a statement of principles from the Endocrine Society. Endocrinology. 2012;153:4097-110.

77. Calabrese EJ, Blain R. The occurrence of hormetic dose responses in the toxicological literature, the hormesis database: an overview. Toxicol Appl Pharmacol. 2005;202:289-301.

78. Rhomberg LR, Goodman JE. Low-dose effects and nonmonotonic doseresponses of endocrine disrupting chemicals: Has the case been made? Regul Toxicol Pharmacol. 2012;64:130-3.

79. Beausoleil C, Ormsby JN, Gies A, Hass U, Heindel JJ, Holmer ML, et al. Low dose effects and non-monotonic dose responses for endocrine active chemicals: science to practice workshop: workshop summary. Chemosphere. 2013:93:847-56.

80. Barouki R, Gluckman PD, Grandjean P, Hanson M, Heindel JJ. Developmental origins of non-communicable disease: implications for research and public health. Environ Health. 2012;11:1-9.

81. Hanson MA, Gluckman PD. Developmental origins of health and disease: new insights. Basic Clin Pharmacol Toxicol. 2008;102:90-3.

82. Bergman A, Heindel JJ, Kasten T, Kidd KA, Jobling S, Neira M, et al. The impact of endocrine disruption: a consensus statement on the state of the science. Environ Health Perspect. 2013;121:104-6.

83. Kortenkamp A, Martin O, Faust M, Evans R, McKinlay R, Orton F, et al. State of the art assessment of endocrine disrupters. [http://ec.europa.eu/ environment/chemicals/endocrine/pdf/sota_edc_final_report.pdf]

\section{Submit your next manuscript to BioMed Central and take full advantage of:}

- Convenient online submission

- Thorough peer review

- No space constraints or color figure charges

- Immediate publication on acceptance

- Inclusion in PubMed, CAS, Scopus and Google Scholar

- Research which is freely available for redistribution

Submit your manuscript at www.biomedcentral.com/submit 